\title{
Abducens Palsy Following Shunting for Hydrocephalus
}

\author{
J.A. Espinosa, M. Giroux, K. Johnston, T. Kirkham and J.G. Villemure
}

\begin{abstract}
Over a period of 12 years, 80 patients underwent ventricular shunting for normal pressure hydrocephalus. Three developed sixth cranial nerve palsy in the first two weeks after surgery. This uncommon complication is usually transitory following the same pattern of abducens palsy after lumbar puncture or spinal anesthesia. Traction on the nerve with local ischemia has been involved as the responsible mechanism in both instances.

RÉSUMÉ: Paralysie du droit externe de l'oeil à la suite d'une dérivation pour hydrocéphalie. Sur une période de 12 ans, 80 patients ont subi une dérivation ventriculaire pour une hydrocéphalie normotensive. Trois ont développé une paralysie du sixième nerf crânien dans les deux premières semaines après la chirurgie. Cette complication peu fréquente est habituellement transitoire et évolue comme la paralysie du droit externe survenant après une ponction lombaire ou une anesthésie spinale. Une traction du nerf accompagnée d'ischémie locale a été invoquée comme étant le mechanisme responsable dans les deux cas.
\end{abstract}

Can.J. Neurol. Sci. 1993: 20:123-125

The causes of abducens palsy are multiple and have been described before in the medical literature. ${ }^{1.2}$ Nevertheless, its occurrence after ventricular shunting for normal pressure hydrocephalus (NPH) is so unusual that it deserves special attention.

\section{Case Reports}

\section{Patient 1}

A 69-year-old male presented with a 4-year history of unsteady gait, progressive memory impairment and recent onset of urinary incontinence. On examination there was difficulty recalling current events, gait apraxia and hyperreflexia of the lower extremities. Computerized tomography $(\mathrm{CT})$ of the brain demonstrated ventricular dilatation. The results of an isotope cisternogram and lumbar subarachnoid infusion test suggested a diagnosis of NPH. A ventriculoatrial shunt was placed and the opening pressure was $18 \mathrm{~cm}$ of CSF. A Pudenz valve with a closing pressure of $5 \mathrm{~cm}$ of $\mathrm{H}_{2} \mathrm{O}$ was used. Postoperative CT scan showed marked decrease in the ventricular size and brain atrophy.

Nine days after surgery the patient complained of nausea and headache followed by double vision when looking towards the right side. The right eye had limited abduction consistent with a sixth nerve palsy. Two days later the headache and nausea disappeared; however the right abducens palsy persisted for nine weeks. His gait, urinary incontinence, and memory improved gradually.

\section{Patient 2}

A 69 -year-old priest with a five-year history characterized by difficulty walking and progressive memory loss was admitted to our institution. Physical examination revealed minimal impairment of recent memory and an abnormal gait characterized by a wide base with short, unsteady steps. The tone was increased in the lower extremities with associated hyperreflexia. CT scan of the brain showed ventricular dilatation. Magnetic resonance imaging (MRI) disclosed a smooth, hyperintense border around the ventricles and marked signal loss in the aqueduct. MRI cine was compatible with NPH. A lumbar puncture was not done as part of his investigations. A ventriculoperitoneal shunt was placed. The ventricular pressure was $15 \mathrm{~cm}$ of CSF and a Pudenz valve with a closing pressure of $5 \mathrm{~cm}$ of $\mathrm{H}_{2} \mathrm{O}$ was used.

On the seventh postoperative day, the patient complained of headache and double vision on either right or left gaze elicited initially only at distant fixation. Two days later it was clear he had developed bilateral abducens palsies. The headache was short-lived. The esotropia improved gradually for six months and then reached a plateau of 16 dioptres on primary, right and left gaze. This required surgical correction 11 months after shunting. His gait improved and one year after surgery the patient returned to his previous occupation.

\section{Patient 3}

A 67-year-old male, retired engineer. was admitted with a history of four years characterized by progressive gait unsteadiness, tendency to drop objects, decreased sex drive and recent inability to concentrate in his daily tasks. Physical examination revealed recent memory impairment, increased tone in lower limbs and bilateral up-going toes. His gait was characterized by short, shuffling steps that improved temporarily after a lumbar puncture. CT scan of the brain showed an enlarged ventricular system with minimal signs of atrophy. MRI findings were suggestive of NPH. He underwent ventriculoperitoneal shunting with no obvious complication during the procedure. The ventricular pressure measured $15 \mathrm{~cm}$ of CSF and a low pressure Pudenz valve with a closing pressure of $4 \mathrm{~cm}$ of $\mathrm{H}_{2} \mathrm{O}$ was used.

Fourteen days after surgery he developed a short episode of nausea, vomiting and severe headache that was followed by diplopia on either right or left gaze. Marked limitation of abduction was seen in both eyes. consistent with bilateral sixth cranial nerve palsies. There were 40 dioptres of esotropia in the primary position. Three weeks later the abducens palsies started to improve and cleared completely 11 weeks after surgery.

From the Division of Neurosurgery (J.A.E., M.G., K.J., J.G.V.) and Neuro-ophthalmology (T.K.), Montreal Neurological lnstitute. McGill University. Montreal

Received March 18, 1992. Accepted in final form October 23, 1992

Reprint requests to: J.G. Villemure M.D., Montreal Neurological Institute, 380I University Street, Montreal, Quebec, Canada H3A 2B4 


\section{Discussion}

Abducens nerve palsy as a complication of ventricular shunting has been reported previously in only two patients. ${ }^{3}$ In those cases and in ours, diplopia developed within two weeks of shunting and was preceded by a short period of headache and nausea. In four of the five patients, the condition cleared within three months. One patient developed permanent bilateral abducens palsies that required extraocular muscle surgery.

The same clinical pattern of sixth nerve palsies may follow lumbar puncture, myelography or spinal anesthesia. ${ }^{4-10}$ It has been proposed that in these cases the mechanism is related to traction on the nerve, resulting from displacement of the brain after loss of CSF support in the basal cisterns." The abducens nerve may be susceptible to traction because it bends abruptly at the petrous ridge to pass forward under the petrosphenoid ligament. ${ }^{11-13}$ Two of our patients had a lumbar puncture as part of the pre-operative investigations; however, these were done well before surgery and could not account for the abducens palsies.

The mechanism outlined above could explain the association of sixth nerve palsies and ventricular shunting. Other mechanical factors like prominent petrous ridges, large branches of the basilar artery crossing over the abducens, and variant courses of the sixth cranial nerve rendering it more susceptible to changes in intracranial pressure have been invoked trying to explain this condition. ${ }^{10}$ These factors, if present unilaterally, could justify the cases of unilateral abducens palsy following ventricular shunting.

The delayed onset of sixth cranial nerve palsy experienced by our patients, associated with headache and nausea, suggest overdrainage of CSF with consequent traction on the nerve (Figure 1). It is not known if this complication could have been prevented by using a valve with a higher closing pressure; however, this is suggested by the fact that all our patients, as well as those reported by Black, ${ }^{3}$ had valves with closing pressures lower than $100 \mathrm{~mm}$ of CSF.

\section{REFERENCES}

I. Glaser JS, Bachynski B. Infranuclear disorders of eye movement. In: Glaser JS, ed. Neuro-ophthalmology. Philadelphia: JB Lippincott Co 1990: 36I-4I8.

2. Keane JR. Bilateral sixth nerve palsy. Arch Neurol 1976; 33: 681683

3. Black PMcL, Chapman PH. Transient abducens paresis after shunting for hydrocephalus. J Neurosurg 1981; 55: 467-469.

4. Drips RD, Vandam LD. Hazards of lumbar puncture. J Am Med Assoc 1951; 147: 1118-1121.

5. Gupta MK, Goldstein JH, Shah M. Epidural anesthesia and VI nerve palsy. Ann Ophthalmol 1980; 12: 571-572.

6. Hayman IR, Wood PM. Abducens nerve paralysis following spinal anesthesia. Ann Surg 1942; 115: 864-868.

7. Miller EA, Savino PJ, Schatz NJ. Bilateral sixth nerve palsy. Arch Ophthalmol 1982; 100: 603-604.

8. Perlman EM, Barry D. Bilateral sixth-nerve palsy after water soluble contrast myelography. Arch Ophthalmol 1984; 102: 968.

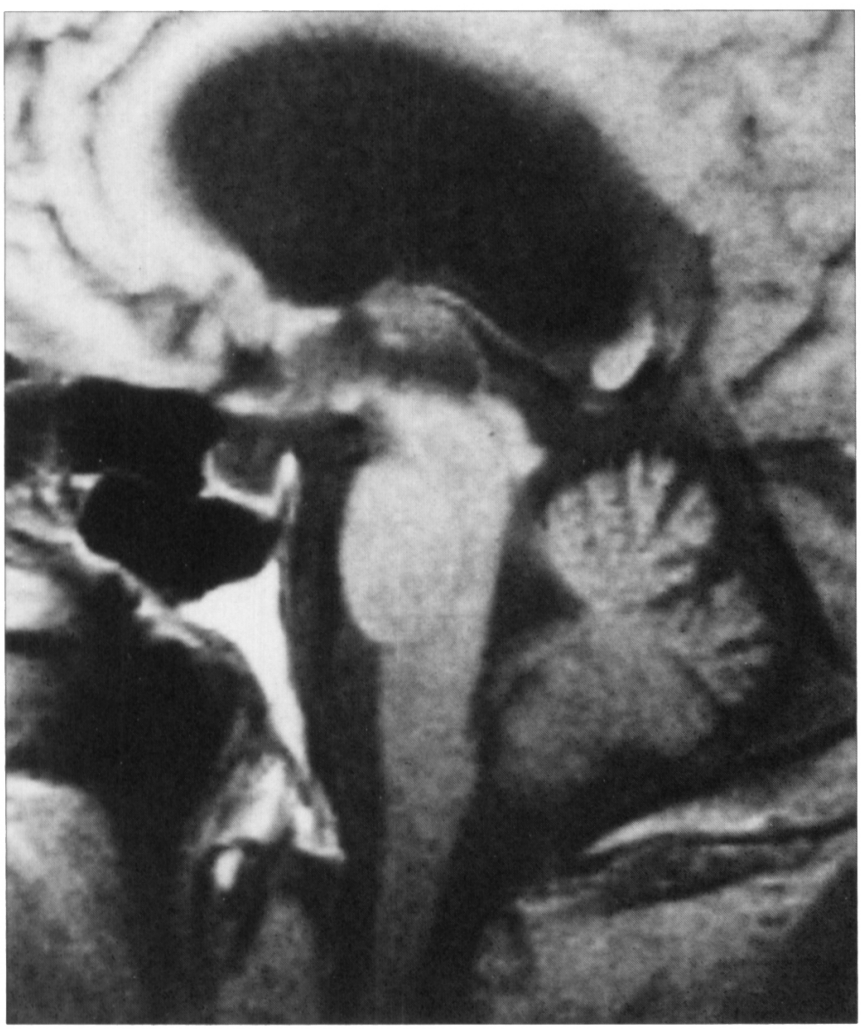

A

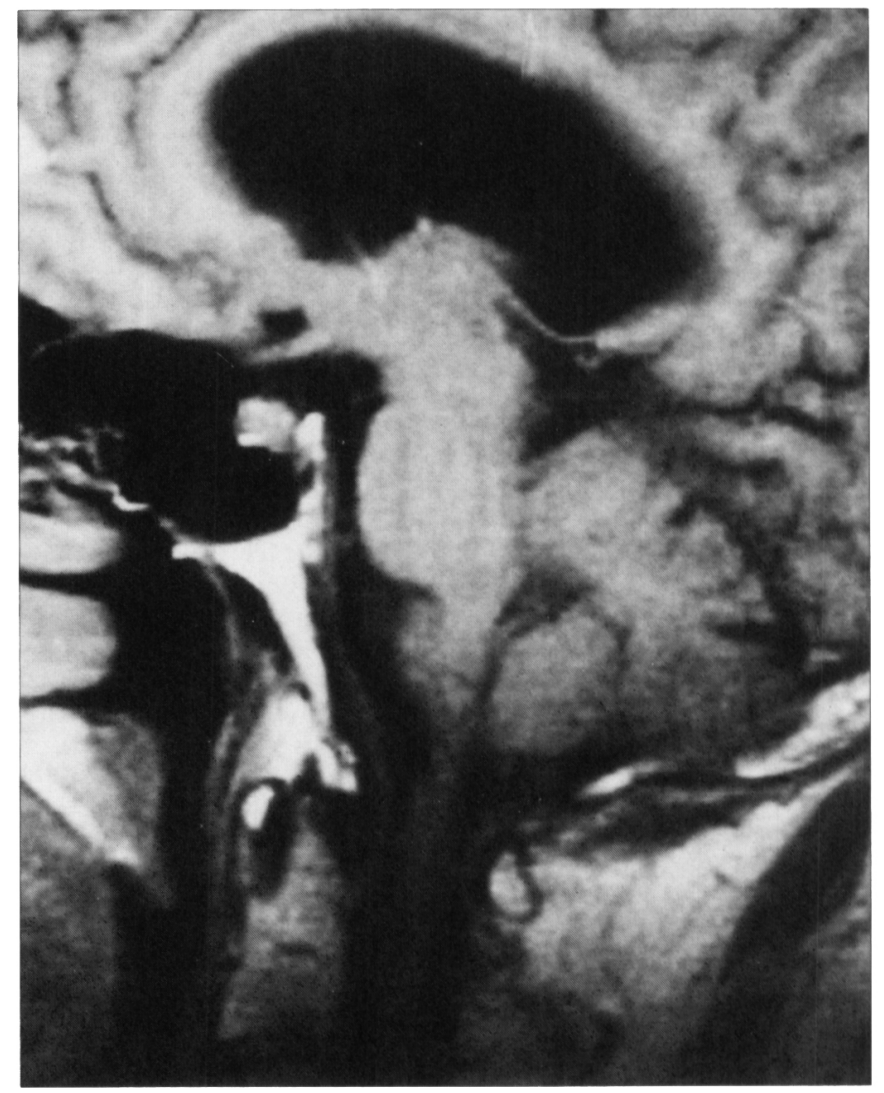

B

Figure I - Pre (A) and postoperative (B) MRI's from patient 2 showing a decrease in the amount of CSF at the pontine cistern after ventriculoperitoneal shunting. This study was obtained seven days after the onset of diplopia. 
9. Fairclough WA. Sixth nerve paresis after spinal analgesia. Brit Med J 1945; 2: 801-803.

10. Seyfert S, Mager J. Abducens palsy after lumbar myelography with watersoluble contrast media. J Neurol 1978; 219: 213-220.

11. Thorsen G. Neurological complications after spinal anesthesia. Acta Chir Scand 1947; 95 (Suppl 121): 1-271.
12. Sachsenweger R. Clinical localization of oculomotor disturbances. $I n$ : Vinken PJ, Bruyn GW, eds. Handbook of Clinical Neurology, Vol 2. Amsterdam: North Holland Publishing Co. 1969; 286-357.

13. Leigh RJ, Zee DS. Diagnosis of peripheral ocular motor palsies and strabismus. In: Leigh RJ, Zee DS, eds. The Neurology of Eye Movements. Philadelphia: FA Davis Co 1991; 291-346. 